\title{
ARE THE ALTERNATIVE ENERGY STRATEGIES ACHIEVABLE?
}

Alvin M. Weinberg

\section{September 1979}

Institute for Energy Analysis

Oak Ridge Associated Universities

Oak Ridge, Tennessee 37830
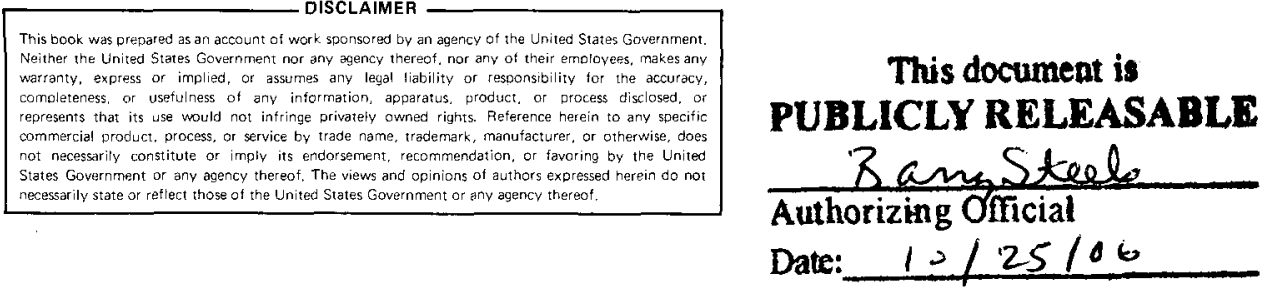

Occasional Papers are publications for which the author assumes primary responsibility and do not necessarily reflect the views of the Institute.

This report is based on work performed under Contract Number DE-AC05-760R00033 between the Department of Energy and Oak Ridge Associated Universities. 


\section{DISCLAIMER}

This report was prepared as an account of work sponsored by an agency of the United States Government. Neither the United States Government nor any agency Thereof, nor any of their employees, makes any warranty, express or implied, or assumes any legal liability or responsibility for the accuracy, completeness, or usefulness of any information, apparatus, product, or process disclosed, or represents that its use would not infringe privately owned rights. Reference herein to any specific commercial product, process, or service by trade name, trademark, manufacturer, or otherwise does not necessarily constitute or imply its endorsement, recommendation, or favoring by the United States Government or any agency thereof. The views and opinions of authors expressed herein do not necessarily state or reflect those of the United States Government or any agency thereof. 


\section{DISCLAIMER}

Portions of this document may be illegible in electronic image products. Images are produced from the best available original document. 


\begin{abstract}
The constraints on penetration of energy technologies are time and information, net energy, and capital cost. As D. Spreng has pointed out, time, energy, and information constitute a triad: energy can be substituted for time, information can be substituted for energy. That energy can save time follows from irreversible thermodynamics, but the principle can be extended to the social sphere. Related to the energy-time exchange is the economic cost of intermittency of energy supply. Renewable energy sources, particularly solar sources, are characteristically intermittent. To eliminate intermittency imposes a cost which must be considered in planning energy futures based on renewable sources. Two other constraints on penetration of energy technologies - net energy and capital cost - are briefly considered. As for net energy, estimates of energy paybacks for solar thermal electric converters differ by factors of three; this introduces large uncertainties in the energy subsidy required for this technology. As for capital cost, the Peterka theory of technological change is shown to place limits on the amount of subsidy required to introduce a new energy technology.
\end{abstract}


Many of the technologies discussed at this conference have long been available; some have been used fairly widely. of the options described here, only two - large-scale solar thermal electric conversion and satellite solar systems - are really unconventional. Why, then, have common technologies such as biomass, wind, geothermal, even conservation, not dominated our energy system?

The simplest answer is that there have been alternatives based on fossil fuels or uranium that have been cheaper. A more sophisticated answer might be that political or administrative decisions have, in some cases, so distorted the economics as to favor one energy option unduly and thus allow it to capture a disproportionate share of the market. The best example of such distortion, I suppose, is the extraordinary growth of the use of natural gas in the United States largely at the expense of coal. This growth occurred because the price of gas was regulated to prevent its rising as the price of competitive fuels rose.

Here I shall try to identify constraints other than the usual economic ones that might limit the penetration of some of the energy alternatives that otherwise seem so attractive. The constraints that I sha1l discuss are time and information, net energy, and capital cost. Most of what I say is drawn from the work of D. Spreng; ${ }^{1}$ W. van Gool; ${ }^{2}$ Vant-Hul1 and Meyers; ${ }^{3}$ S. Baron $;^{4}$ W. Devine, D. Boyd, and W. Gilmer; ${ }^{5}$ K. Cohen; ${ }^{6}$ and V. Peter̀ka. 7

*Presented at the Conference on Energy Alternatives, United Nations University, Honolulu, Hawaii, January 11, 1979. 
On Time, Energy, and Information

In a recent paper, "On Time, Information, and Energy Conservation," Daniel Spreng of Alusuisse Ltd. and the Institute for Energy Analysis has examined the triad: time, energy, and information, and has shown that to a degree, each of these is exchangeable for the other. Spreng first asks the question, If conservation of energy is such a good thing, why haven't we conserved as much as possible already?

The simple answer is that our energy system has been shaped by economic forces. If energy is cheap, there is little incentive to conserve. When energy becomes scarce, or at least more expensive, then conservation takes hold.

But this, as Spreng argues, is an oversimplification. Time is also a limited resource and in some cultures is valued very highly. That time and energy are often conjugates in the sense that to do a task more quickly usually requires more energy (not merely more power) follows from irreversible thermodynamics. A reversible process requires infinite time; the faster the process is performed, in general, the less is its energy efficiency.

This exchange of energy for time has long been known to designers of process equipment. Professor Robert Essenhigh ${ }^{8}$ of Ohio State University has given a general theory of the loss of furnace efficiency as the rate of production increases. If one considers, say, a brick kiln whose output is measured by the amount of heat $\mathrm{H}_{\mathrm{S}}$ transferred to the 
product per unit time (this would be a measure of the number of bricks produced per day), then the input enthalpy to the furnace $\left(\mathrm{H}_{\mathrm{f}}\right)$, under very general conditions, obeys an equation of the form

$$
H_{f}=H_{f}^{O}+\frac{H_{s}}{\alpha^{o}\left(1-H_{s} / H_{s}^{m}\right)}
$$

where

$$
\begin{aligned}
\mathrm{H}_{\mathrm{f}}^{\mathrm{o}}= & \text { enthalpy required to balance wall loss, etc. ("idling" } \\
& \text { enthalpy) } \\
\mathrm{H}_{\mathrm{S}}^{\mathrm{m}}= & \text { maximum output corresponding to adiabatic flame temperature } \\
& \quad \text { (no heat loss); } \alpha^{0}=\text { constant. }
\end{aligned}
$$

Equation (1) is concave upward in the region of practical design (Figure 1); it illustrates the point that to increase the production rate costs energy per unit of production, or, as van Gool puts it, haste makes waste.

Another example is seen in Figure 2, which is cited in Spreng's paper. Here is plotted the efficiency of an automobile as a function of road speed. The efficiency falls at speeds higher than about 30 miles per hour, the drop-off being sharper for lighter cars. (At very low speed the efficiency is, of course, low since some energy is required to overcome engine friction and to idle the engine.) Nevertheless, despite the lower efficiency at higher speed, people seem to be reluctant to give up the time that operation at the optimum would entail. This point was the subject of an editorial in Newsweek of October 23, 1978, where Professor Charles A. Lave complained that the 55-mile speed 1 imit cost 
$-4-$

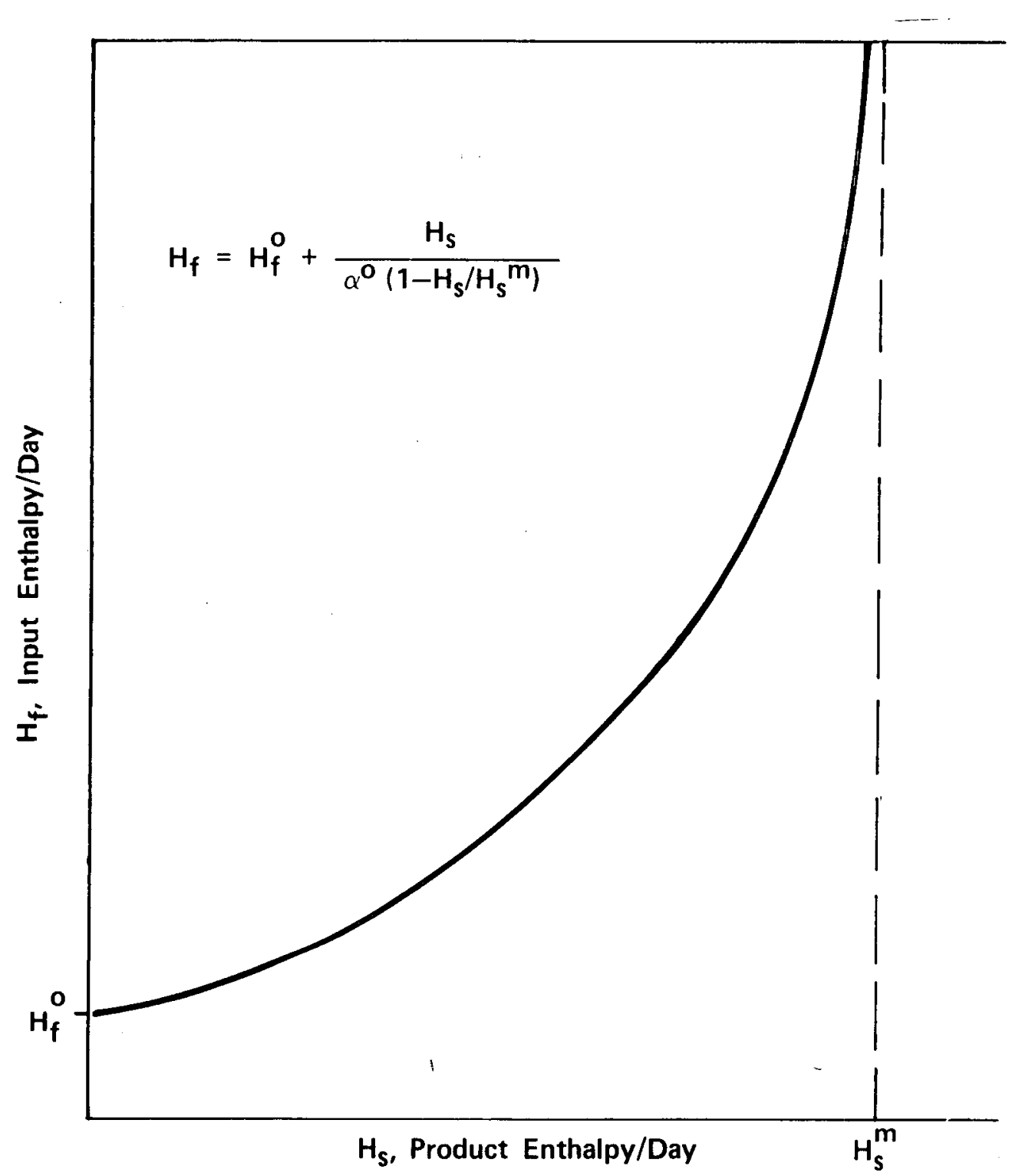

FIGURE 1: INPUT ENTHALPY AS FUNCTION OF RATE OF PRODUCTION (After Essenhigh ${ }^{8}$ ) 


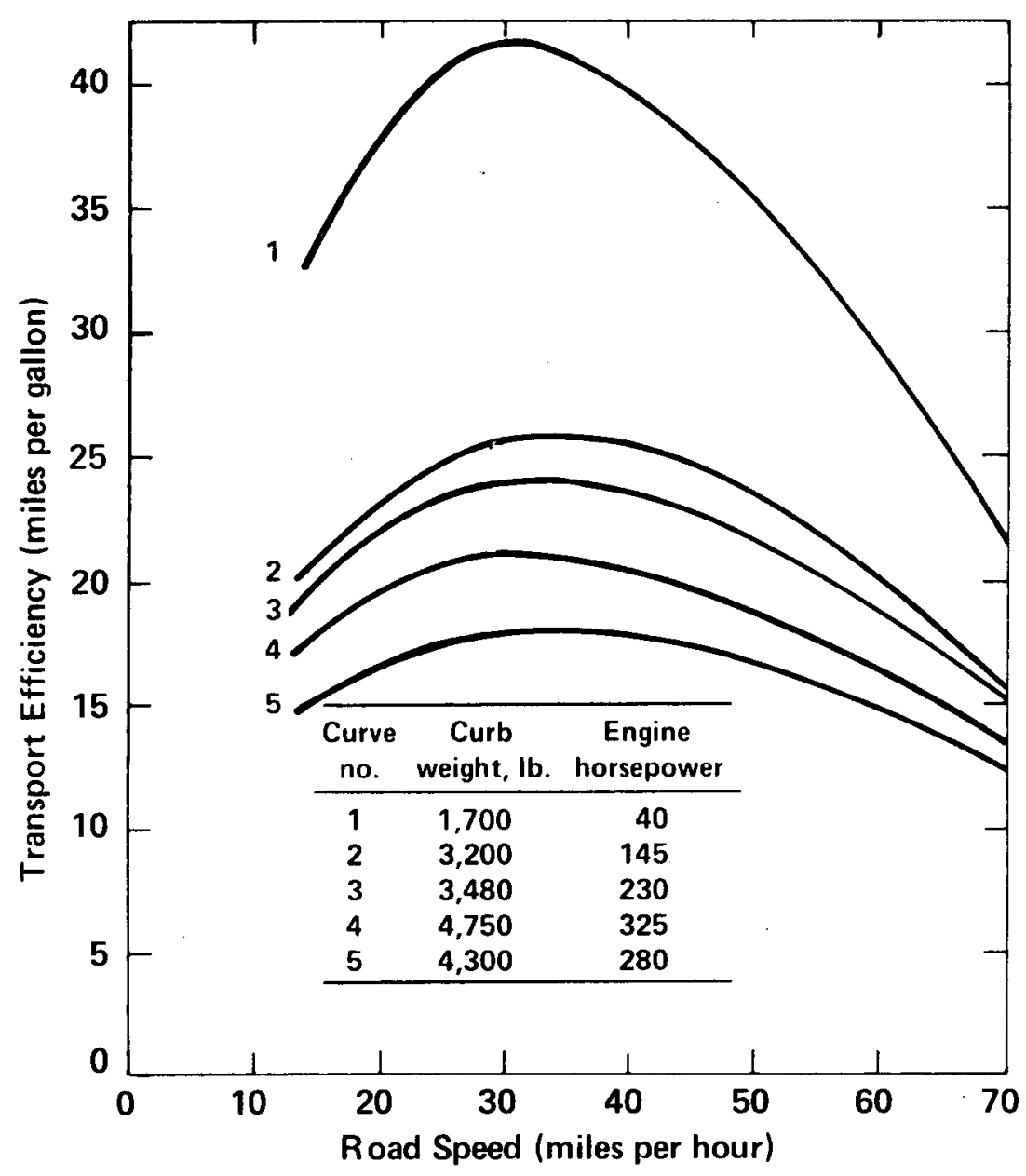

FIGURE 2: EFFICIENCY OF AUTOS AS FUNCTION OF ROAD SPEED (from R. Winfrey ${ }^{9}$ ) 
the United States about $10^{6}$ man-years per year; the saving in oil is perhaps 0.2 quads.

Where Western man has a choice, he usually chooses technologies that save time. The ability to allocate time as one chooses, rather than as dictated by the vagaries of nature, is an attribute of human freedom. The galley slave is the epitome of man bereft of freedom; he had essentially no power to allocate his time. The power that the Industrial Revolution gave to man in harnessing fossil energy was in good measure the power to allocate time.

Spreng has used data collected by A. Szalai ${ }^{10}$ to correlate free time against energy use per person in 11 different countries. His correlation is shown in Figure 3. As plotted, one can hardly say that free time is correlated with specific energy use, although, except for Peru, there seems to be some relation between the two. On the other hand, Spreng points out that the large amount of free time found in Peru (a low energy society) may be explained in part by the large number of students in the sample, the presumption being that students may have more free time than do regular workers - at any rate, a student usually spends in class about half as much time each day as a worker spends on the job. Also, Spreng argues that in countries reporting relatively little free time per unit of energy, most women work; the reverse is true in countries with more free time. If one counts these two classes of countries separately, the correlation between free time and energy is improved.

Conservation is of two kinds: measures, such as reducing output rate or speed, that affect our lifestyle (often in a way that many of 


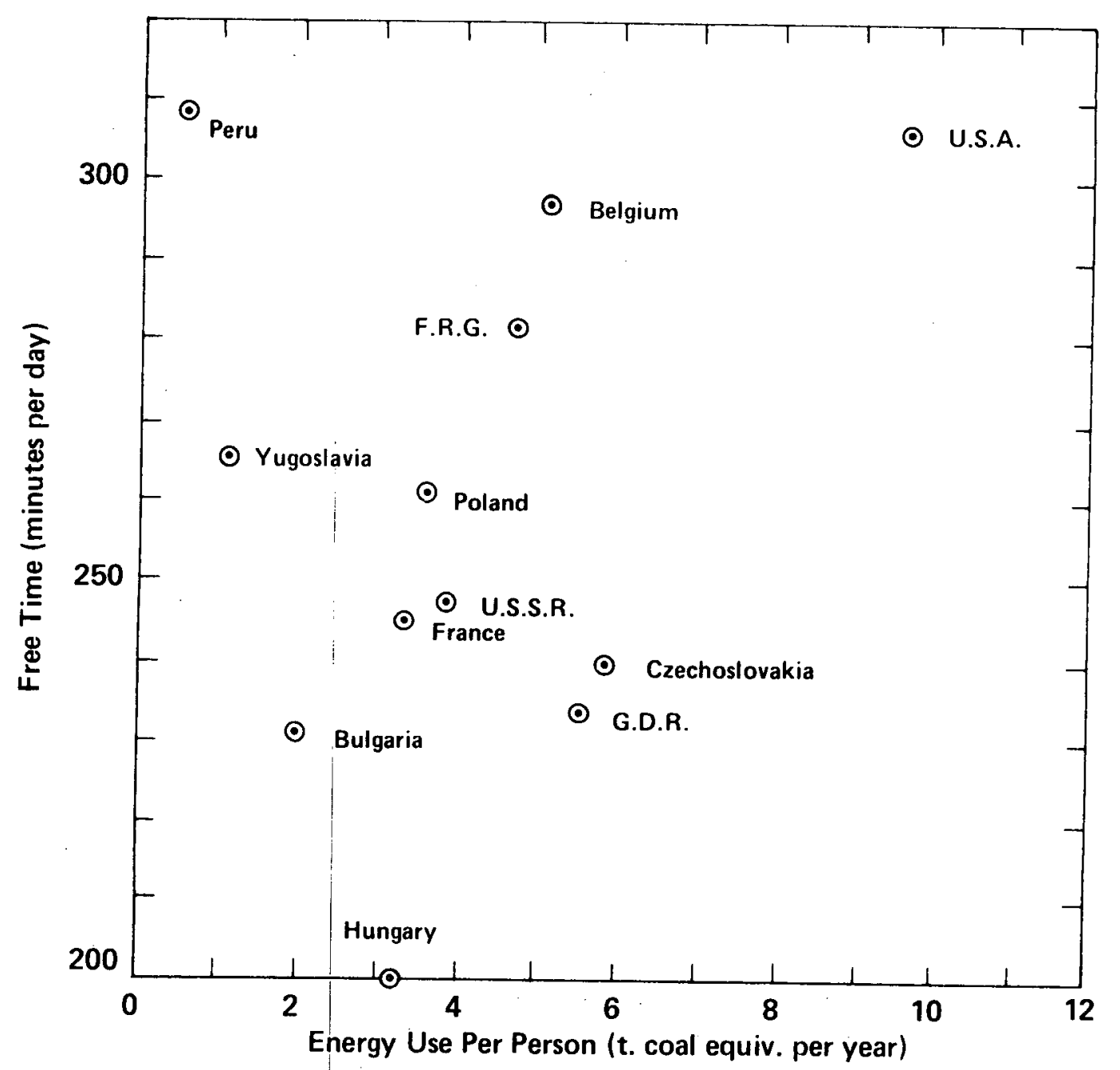

FIGURE 3: FREE TIME VS. ENERGY USE IN VARIOUS COUNTRIES (After Szalai ${ }^{10}$ and Spreng ${ }^{1}$ ) 
us would find somewhat objectionable); and technological measures that achieve the same output with lower energy input, and therefore do not affect our lifestyle, but which require additional capital equipment or technical innovation. Now, as van Gool and Spreng independently have pointed out, such capital equipment itself embodies energy; moreover, this energy must be spent at the outset. It is an investment that is repaid over the lifetime of the equipment. Where the energy optimum (including both capital energy and operating energy) lies depends upon the period over which the equipment is amortized. If the amortization is very short, it does not pay to spend very much capital energy since the capital energy is lost when the equipment is retired (unless the materials can be recycled); conversely, if the amortization is long, the optimum capital energy is correspondingly larger. This is illustrated in Figure 4, where Spreng plots the energy requirement for heating and insulation as a function of insulation thickness and of energy amortization time. As one sees, the optimum insulation thickness in his example lies at $10 \mathrm{~cm}, 24 \mathrm{~cm}$, and $38 \mathrm{~cm}$ for amortization times of 2, 10, and 50 years respectively.

Spreng stresses that the appropriate amortization time is uncertain: if one builds a house, there is always a chance that one will move away before the mortgage has been paid, or even that the house might burn down. This lack of certainty, or as Spreng puts it, lack of information, itself affects the energy optimum. An uncertain perception of the future favors lower capital investment and higher operating costs; if one confidently 


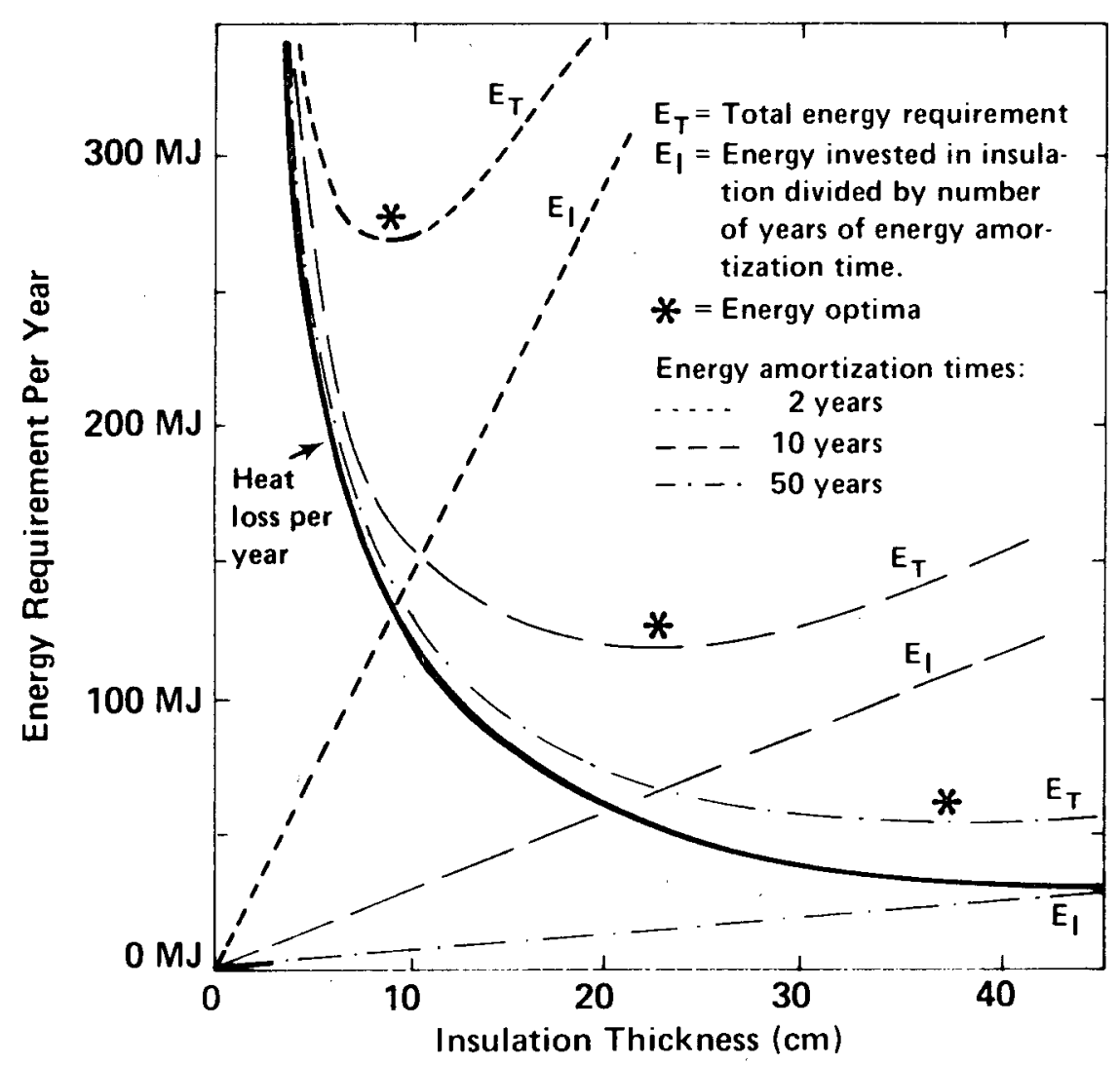

FIG̈URE 4: ENERGY REQUIREMENT FOR HEATING AND INSULATING AS FUNCTION OF INSULATION THICKNESS

$$
\text { (After Spreng }{ }^{1} \text { ) }
$$


looks forward to a very long future, then one builds things to last a very long time, and sturdy buildings embody more energy than do flimsy ones.

Spreng visualizes time, energy, and information as forming a triad: each, to some extent, is substitutable for the others. Thus by going slower (and spending time) we can save energy; or if we have more information - say, of the future - or are more technologically sophisticated, we can better optimize the design of our energy system; or if we are prepared to waste energy, we can often save time or make up for lack of information (for example, by grossly overdesigning a reactor pressure vessel, and thus increasing its embodied energy to make up for our inability to calculate in detail its thermomechanical behavior under radiation and temperature stresses).

These ideas are summarized in what I ca11 the Spreng triangle (Figure 5). This is a three component "phase diagram" in which the state of the system is characterized by the three parameters: time, energy, and information. The sides of the triangle correspond, respectively, to maximum available energy (Modern Industrial Man), maximum available time (The Primitive Savage), and maximum available information (The Starving Philosopher). As indicated, if an individual, or an organization, or a country is in a state characterized by the use of specific amounts of energy, available time, and available information, then one can save energy (as indicated by the arrow 1 abeled $-\Delta E$ ) by using more time $(\Delta t)$ and more information $(\Delta I)$. Of course, the units 


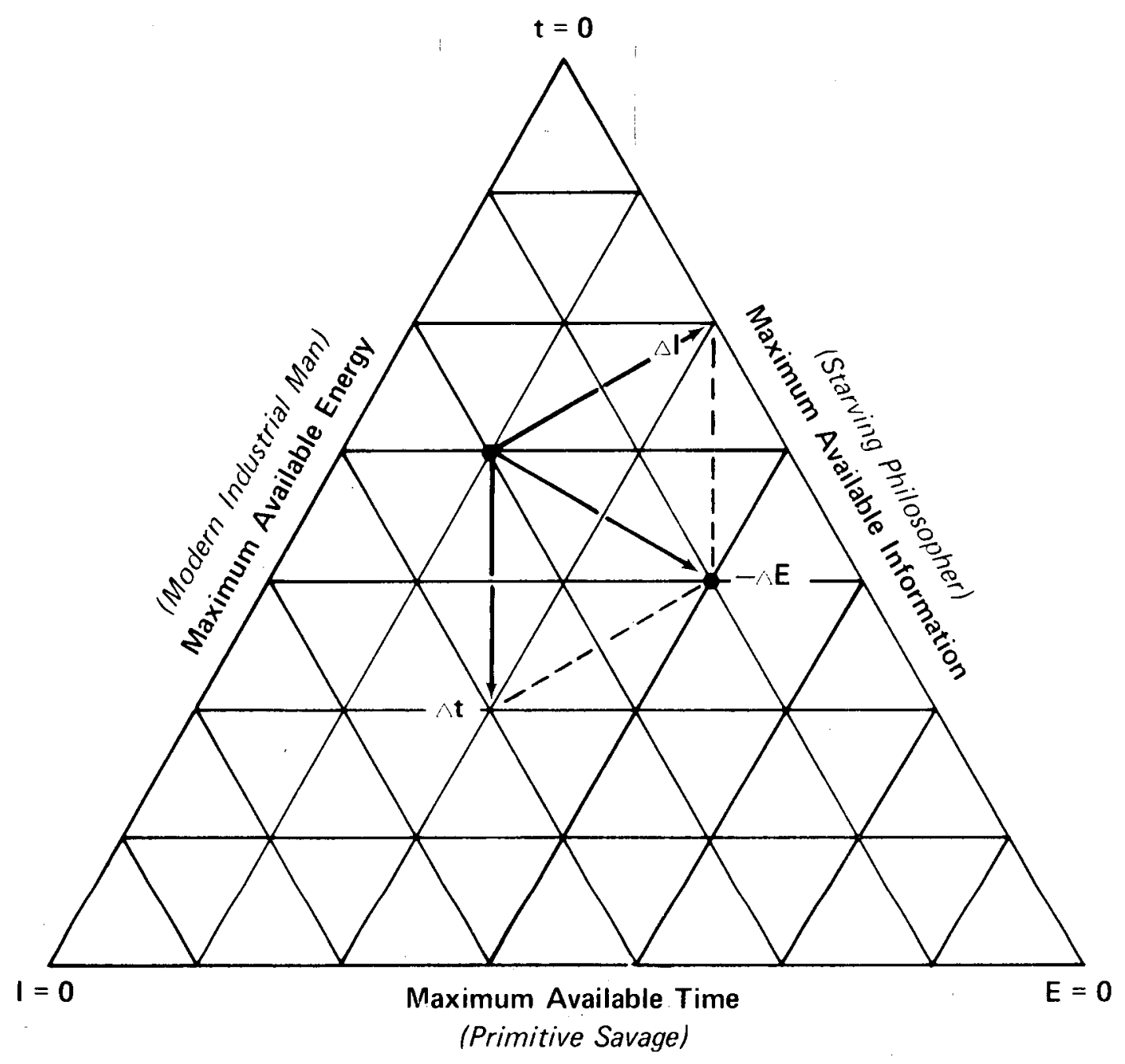

FIGURE 5: THE SPRENG TRIANGLE 
of time, information, and energy are quite arbitrary: the vector decomposition of $\Delta \mathrm{E}$ into $\Delta t$ and $\Delta \mathrm{I}$ is merely schematic.

To be sure, Spreng's considerations have a rather philosophic, almost a poetic quality. Nevertheless, I believe he catches the essence of the underlying energy dilemma: Western man, especially in the United States, has been driven to exploit his energy resources by his desire to allocate time as he wishes. In this exploitation his control over information allows him to be more efficient. But the rate at which new energy technologies, especially conservation, will in fact be introduced will depend on how we perceive the trade-off between time and other resources, and our sophistication and understanding of the new technologies. Thus a conservation measure doesn't happen automatically: it happens only if the economic penalties imposed by not conserving outweigh, in the individual's perception, the loss of time that the conservation measure entails; or if the individual can be persuaded to take a view of the future that is long range enough to justify his investing in the additional capital equipment necessary to save energy over the long run.

\section{Intermittency: Its Cost}

Closely related to the time-energy trade-off is the matter of intermittency of energy supply. If, as some propose, our future is to depend entirely on renewable resources - i.e.,. upon the sun - then we must come to terms with intermittency. For some, this is a small matter: after al1, the construction industry and much of agriculture is conducted 
intermittently. When it rains, bricklayers stay home; despite the randomness of inclement weather, construction has adapted to this inconvenience.

Nevertheless, most industry finds intermittency wasteful. Can we estimate the cost of intermittency? The Ontario Hydro company tried to do this ${ }^{11}$ by asking its largest industrial customers to estimate costs of power outages of different durations, from one minute to one day. The responses are shown in Figure 6. Generally speaking, an unexpected outage was more costly than one that was expected and could be prepared for; and a short outage was, per kilowatt hour, more expensive than a long outage. Of course, as Gilmer ${ }^{5}$ points out, an outage that is so long as to jeopardize the plant or the solvency of the company would be catastrophically costly.

Thus, in considering alternative energy technologies in a $30 \mathrm{TW}$ world, it will be necessary to consider intermittency seriously. To be sure, the prospectus for this conference stressed the necessity for diversity of energy supplies, and if supply is sufficiently diverse, intermittency will be reduced. But one can imagine a scenario that denies the world its nonintermittent alternatives: fossil fuel if $\mathrm{CO}_{2}$ is deemed really serious; nuclear fission if it proves politically unacceptable; fusion if its technology remains insurmouritable. What, then, would the world do if it had to get along only on solar energy with a little geothermal and tidal energy?

This possibility seems so remote that policymakers generally ignore it. To me it seems to be central to the great debates on energy policy: 


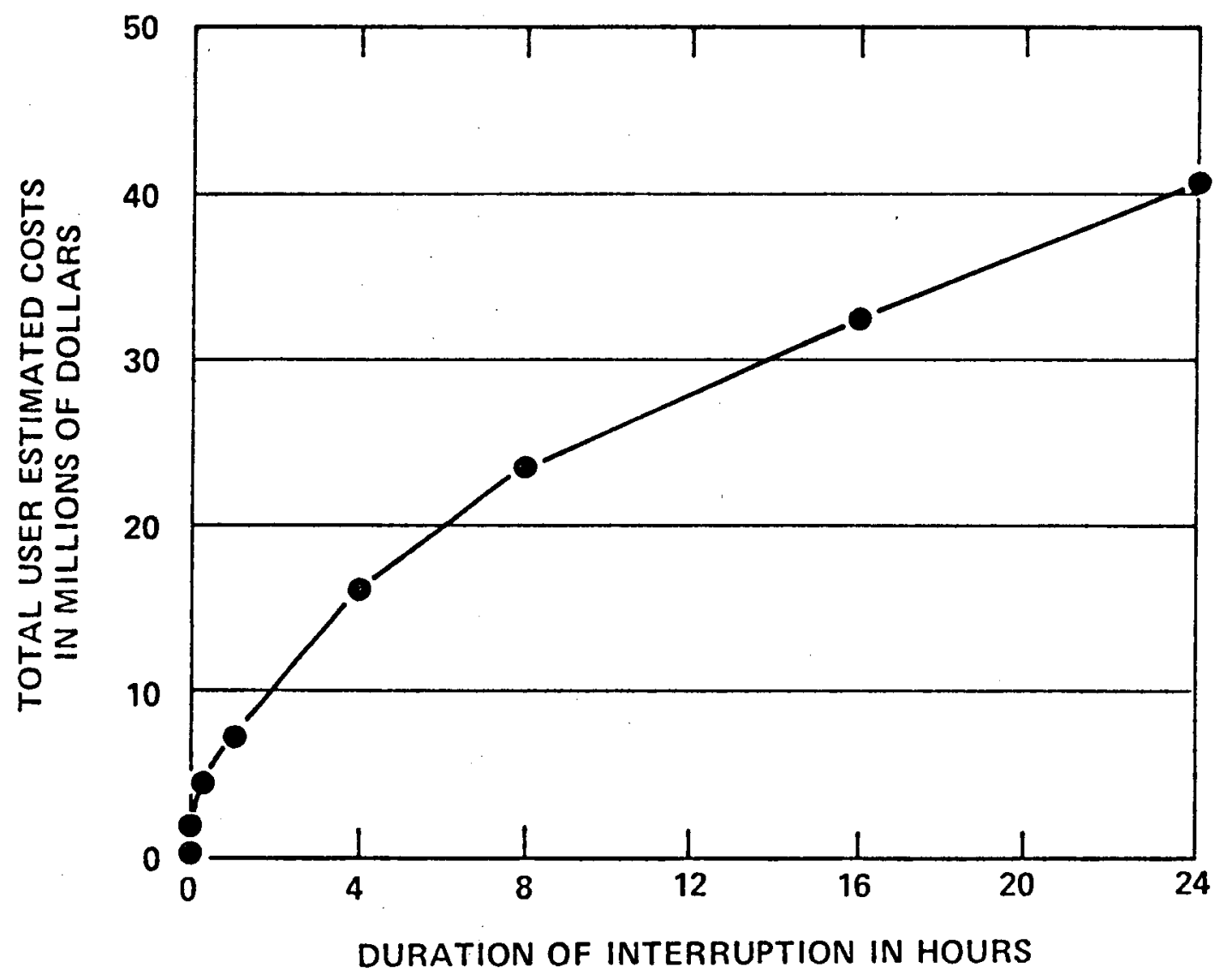

FIGURE 6: ESTIMATES OF COST OF ELECTRICAL SERVICE INTERRUPTIONS FOR 115 LARGE INDUSTRIAL CUSTOMERS OF ONTARIO HYDRO 11 
the implicit, and often not so implicit, assumption of many who argue against the nuclear option is that solar energy can do the job. But if solar is to stand by itself unsupported by a powerful nuclear or fossil-based grid, then the issue of intermittency becomes central.

In principle, we can eliminate intermittency by providing a sufficiently large storage or fuel-based backup system; or by intertying the intermittent system to a large enough grid (though in the latter case there is always the possibility of a massive system failure). The question is, How much would we have to pay to eliminate intermittency in a largely solar society? W. Devine, D. Boyd, and R. W. Gilmer have been studying this question at the Institute for Energy Analysis. Although our studies are unfinished, our approach may be of interest to this conference.

Devine et al. consider a society in which energy services are provided primarily by solar flux sources. They seek to determine the cost of such services as a function of the intermittency of the system. The system is characterized by five parameters:, collector area, A; storage capacity, C; auxiliary fuel or electricity used, F; auxiliary system capacity, B; and the degree of intermittency in energy supply caused by variation in the solar flux. The latter is determined by the solar insolation at the site, by collector area $\mathrm{A}$, and by storage capacity $\mathrm{C}$. The cost of intermittency depends upon the energy service: for example, interruption of electric power is better tolerated in an office than in an aluminum plant. If we designate the average annual cost incurred by 
a pattern of intermittency by $\bar{I}(A, C)$, and the price associated with the $i^{\text {th }}$ component of the system by $P_{i}$, the cost of energy service is

$$
K=P_{A} A+P_{C} C+P_{F} F+P_{B} B+\bar{I}(A, C) .
$$

The amount and therefore the cost of intermittency can be reduced by increasing $A, C$, or $B$. Thus it seems plausible that there exists an optimum set of A, C, F, and B which will yield a minimum cost for delivered energy service. 'In this formulation the cost of intermittency is treated in the same way as are the other costs.

We have completed a few baseline calculations in which the backup is firm so that $\bar{I}(A, C)=0$. Thus, for process heat in Boston, with fuel costing $\$ 10 / G J$, we find the optimum at 61 percent solar and an average cost of energy service of $\$ 9.7 / G J$; if the fuel cost rose to $\$ 30 / G J$, the optimurn solar fraction increases to 85 percent, and the cost of energy service to $\$ 14 / G J$. These numbers, though illustrative, show how the fraction of energy supplied by the solar component increases as fuel costs rise, but also show that the fuel cost must be very high indeed for solar (in Boston) to take over 85 percent of the load.

Gilmer and Devine at IEA have been attempting to estimate $\bar{I}(A, C)$, the cost of intermittency, by dividing $\bar{I}$ into two parts - the direct cost $I$ of shutting down the plant, plus $h$, the cost of uncertainty about the timing and length of these shutdowns. The direct cost for the outage can be estimated, in principle, from the loss of production and the carrying charges on idle capital equipment; the cost $h$ is related to the 
amount of insurance required to forestall the possibility that the firm might go bankrupt because of repeated extensive shutdowns. Numerical values for I can be estimated from the Ontario Hydro data, but it must be admitted that much more work is required before one can assign plausible values to the cost of intermittency. My own impression is that the cost of intermittency will eventually be recognized to be a highly significant part of the analysis of energy systems that depend on solar flux sources. If intermittency is shown to be as costly as suggested by the Ontario Hydro study, then I should think the decentralized ideal of many sma11, independent units may be hard to attain. In any event, the higher the cost of intermittency, the larger the amount of energy that must be embodied in the backup system to avoid intermittency.

\section{Net Energy Constraints}

Another constraint on introduction of a new technology is its embodied energy - for example, the energy embodied in a solar thermal electric system (STEC). I have not tried to compute the net energy balance for the solar thermal electric system. I am therefore puzzled by the discrepancy of about a factor of 3 between two recent net energy analyses of 100 MWe solar thermal conversion systems. A. C. Meyers and Lorin L. Vant-Hull claim the pay-back time for a plant in the Southwest is 1.7 years; Baron claims it is 4.6 years. The analysis by Meyers and Vant-Hull was based on the McDonnell-Douglas/University of Houston design 
with 6 hours of storage; Baron's analysis was based on the Energy Research and Development Administration environmental assessment of a 100 MWe STEC plant plant with 4 hours of storage. Baron gives both the range of materials as given in the ERDA assessment and a figure 50 percent higher which, according to him, is what the actual material requirement is likely to be. In Table 1, I have compared the two estimates of the four materials - steel, concrete, glass, and aluminum - that contribute more than 90 percent to the embodied energy.

The main differences between the two estimates are in the amount of steel (factor $\sim 3$ ), aluminum (which seems to be hardly used in the Meyers/Vant-Hul1 design), and the concrete pad (Baron assumes a 6" concrete pad, 1.3 square miles in area, as a base for the heliostats and as a means for handling drainage and controlling dust and dirt).

TABLE 1: ESTIMATES OF MATERIALS AND EMBODIED ENERGIES REQUIRED FOR 100 MWe STEC

\begin{tabular}{|c|c|c|c|c|c|}
\hline & \multicolumn{2}{|c|}{ Vant Hull/Meyers } & \multicolumn{3}{|c|}{ Baron } \\
\hline & \multicolumn{2}{|c|}{ Tons/MWe } & \multicolumn{2}{|c|}{ Tons/MWe } & Total Energy \\
\hline & & & Estimated & Expected & $\left(10^{9} \mathrm{Btu} / \mathrm{MWe}\right)$ \\
\hline Steel & & 375 & $500-700$ & 1,050 & 51 \\
\hline Concrete & & 2,000 & $1,500-2,500$ & 3,750 & 6 \\
\hline Glass & & 140 & 50. 100 & 150 & 3 \\
\hline Aluminum & & Small & $20-50$ & 75 & 21 \\
\hline $6^{\prime \prime}$ mat. (1- & $\left.M i^{2}\right)$ & - & & 13,600 & 21 \\
\hline Others & & - & -- & - & 12 \\
\hline
\end{tabular}


The uncertainty surrounding net energy analysis of STEC is uncomfortably large. Whether this uncertainty is likely to be diminished in the near future I rather doubt. After a11, it took about 4 years of bickering among energy analysts before they agreed upon the net energy analysis for light water reactors, even though more than 100 had been built. Although older incorrect estimates of payback times for nuclear reactors made nuclear energy unacceptable in an expanding system, the fact remains that any new technological system - OTEC, STEC, even conservation systems - does cost energy if it is deployed very rapidly.

D. Boyd of IEA has computed the net energy yields or subsidies for a system that, starting at the present 0.001 quads/year, doubles each year for the first 9 years, and then increases 1 inearly at about 0.25 quads/year until the total installed reaches 25 quads/year by about A.D. 2000. (This scenario is suggested by the Council on Environmental Quality's recent goal of about 25 quads of solar energy by 2000.) Boyd finds for energy payback periods of 2, 3, and 5 years, maximum subsidies of 3,7 , and 30 quads, respectively. These are far lower than the maximum subsidy of 50, 75, and 125 quads which would be incurred if the 25 quads/year were installed in a single year. Of course, these energy subsidies must be compared to the energy outlay required for alternative ways of achieving the same additional capacity. Nevertheless, these considerations suggest that net energy during the growth phase may constitute a constraint on the rate at which the new technologies are put in place. In any event, claims as to energy saved during the introduction of the new technologies ought to be tempered by consideration of net energy. 
Capital Cost and Market Penetration: The Peterka Theory

Let me turn now to still another factor that will determine the rate at which alternative technologies will penetrate: capital cost. Here I draw from work done by K. Cohen and V. Peterka. ${ }^{6}, 7$

As many in the audience know, Fisher and Pry ${ }^{12}$ in 1970 observed that a new technology tends to displace an older technology according to the relation

$$
\text { In } f_{2} / f_{1}=\text { At }
$$

where $f_{1}$ is the market fraction of the old technology, $f_{2}$ is the market fraction of the new technology, $A$ is an empirical constant, and $t$ is time. If these are but two competing technologies, $f_{1}=1-f_{2}$, and Equation 2 represents the familiar logistic growth. Fisher and Pry found this relation to hold for 17 competing technology pairs ranging from the basic oxygen furnace/open hearth to synthetic rubber/natural rubber.

V. Peterka has offered a rationalization of the Fisher-Pry relation. He assumes that after an initial period during which a new technology might be force-fed by government subsidy, a technology eventually expands at a rate such that the profit generated by that technology pays for its own expansion. If $P_{i}$ is the rate of production by the $i^{\text {th }}$ competing technology, $\mathrm{P}_{i}$ is the market price of a unit of production, $c_{i}$ is the cost, including capital charge, of producing one unit, and $\alpha_{i}$ is the capital needed to increase the production rate one unit, then the 
Peterka idea is embodied in the following equation:

$$
\alpha_{i} \dot{p}_{i}(t)=P_{i}(t)\left[p_{i}(t)-c_{i}\right] i=1,2, \ldots, n
$$

Integration of Equation 3 for two technologies that compete for the same market and therefore charge the same price for this output leads essentially to the Fisher-Pry relation with

$$
\mathrm{A} \simeq \frac{\mathrm{c}_{1}-\mathrm{c}_{2}}{\alpha}=\Delta \mathrm{c} / \alpha \text { in the case } \mathrm{n}=2, \alpha_{2}=\alpha_{1}=\alpha
$$

In this simplified case, the rate of penetration is determined by $\Delta c / \alpha$; unless the cost advantage is large compared to the capital cost, the penetration rate will be slow.* According to the Peterka theory, in the case of equal capital cost, the introduction rate (tine to achieve an e-folding of the market penetration) is $\alpha / \Delta c$, i.e., if the difference in cost per kilowatt-year between the new technology and the old is, say, 5 percent of the capital cost per kilowatt, then the ratio $f_{2} / f_{1}$ would increase by $e$ in 20 years. If the initial penetration were 2 percent, the penetration would be 5 percent in 20 years. Thus even if the capital costs of the new and old technology are the same, high capital cost,

\footnotetext{
*As an aside, I point out that Peterka's underlying idea - that each new technology must pay for its own expansion - is reminiscent of Soviet economic thinking of about 15 years ago. At that time the idea of "socialist rate of return" - namely the right-hand side of Equation 3 was introduced. The principle was then proposed that the proper socialist rate of return for each segment of the economy (i.e., profit in capitalist economics) was to be determined so as to match the rate of increase of capitalization of that segment: i.e., instead of using Equation 3 to determine the rate of penetration, the rate of penetration was to be used to determine the price and therefore the profit or "socialist rate of return." In the old Soviet literature this idea was used to criticize Stalin's overinvestment in hydro and underinvestment in thermal power plants, with the rest of the economy in effect subsidizing the hydro plants.
} 
relative to the savings in overall cost, $\Delta c$, means slow market penetration. A more accurate integration of Peterka's equations shows that the penetration is even slower if the capital cost of the new technology is higher than that of the old.

These considerations might be of interest to all of us interested in penetration of new technologies: they imply that if the market works as Peterka suggests, then a new technology will penetrate rapidly only if the gain in cost per unit of product is fairly appreciable compared to the capital cost of the technology that is being displaced.

I have tried to apply the Peterka theory to estimate what ratio $\Delta c / \alpha$ is required if solar energy were to penetrate by a certain amount in the year 2000 only through the working of the market. Let us assume that the fraction of solar to nonsolar sources in 2000 is $R$ times the fraction in 1980. Then, according to Peterka,

$$
\frac{\Delta \mathrm{c}}{\alpha}=\frac{1}{20} \ln \mathrm{R}
$$

To achieve a hundredfold penetration, $\Delta c / \alpha$ must be $0.23 /$ year; to achieve a twentyfold penetration $\Delta c / \alpha$ must be 0.15 . If we take $\alpha \simeq \$ 4000 / \mathrm{kW}$, then $\Delta c$ must be $\$ 920 / \mathrm{kWyr}$ in the first case, $\$ 700 / \mathrm{kWyr}$ in the second case. Thus the savings in cost between the old technology and the new would have to be between $6.8 \phi / \mathrm{kWh}$ and $10,5 \phi / \mathrm{kWh}$.

Can the Peterka theory be turned around to allow one to estimate what subsidy might be required to achieve a twentyfold penetration by 2000 ? The above example suggests that $\Delta \mathrm{c}$ must be $6.8 \$ / \mathrm{kWh}$ for this to happen. Since 
it is most unlikely that any of the solar electric schemes will produce electricity more cheaply than the alternatives, I should think this is a lower limit to the size of the required government subsidy.

This example doesn't prove very much, since the requirement that the new technology must be less costly than the old one can hardly be realized over the next 20 years. Moreover, according to the Peterka theory, small cost advantages at the margin are not sufficient to bring the new technology in quickly: the cost advantages would have to be large, especially if the capital costs of the new technology are higher than of the old. But more fundamentally, the underlying assumption in the Peterka theory that the new technology must pay its own way - is probably unjustified. If our society decides to go solar then it can do so: if solar costs more, then a political decision - to tax other forms or to subsidize the more desirable form - can make this happen. But the main point is that a political decision - a heroic decision as Kenneth Boulding calls it would have to be made. This must be recognized as a fundamental constraint or requirement when we try to decide which of the substitute technologies are in fact achievable.

I present these computations based on the Peterka theory with diffidence since there is much controversy as to whether market forces have very much to do with penetration of new technologies. H. G. MacPherson of IEA has pointed out that the American Telephone and Telegraph Company has expanded enormously yet its yearly cash flow (represented by the right side of Equation 3) has never equaled the yearly increase in capitalization. An 
expectation of larger profit in the future ensures the marketability of ATET stocks and bonds. Thus in this case, the expansion does not work exactly as Peterka visualizes. Nevertheless, it seems to me there is some relation between cash flow and investment: perhaps not as Peterka says, but rather that the cash flow at some time $T$ in the future must be enough to cover the cost of expansion. Over the long run, investors put their money where experience has shown their investment is profitable. And, as MacPherson says, why not simply concede that for a new technology that shows no economic benefit to prevail (like solar electricity or, perhaps, breeders) a government subsidy is required. The minimum subsidy brings the price of the new technology to parity with the old. From then on, the new technology will penetrate at a rate determined by additional subsidy or legal restraints on the competitive technology - e.g., Brazil may decide to prohibit oil imports once it has capacity to produce enough gasohol.

Yet I believe Peterka ought not be rejected so thoroughly. It seems reasonable to expect high capital cost to be a deterrent to introduction of technology if the marketplace is operating. If it is not, as in the introduction of hydro electricity in the Soviet Union, then of course one can make no predictions. But I repeat, a "heroic decision" is then required if the new technology is to penetrate - and one must recognize that such political decisions are necessary. 


\section{Conclusion}

Clearly, each of the constraints I have touched upon require more careful analysis that I have given here. My main purpose has been to remind this conference that time and information, net energy, and capital cost impose constraints on the rate of introduction of new energy technologies that cannot be ignored by policymakers. This is hardly new, or startling. Indeed, the one energy technology that has penetrated despite these constraints, nuclear energy, did so because it was subsidized by the government in the form of support for R\&D and demonstrations, by reactor vendors who in aggregate in the United States have lost perhaps $\$ 10^{9}$ on the reactor business. The other new technologies will also require subsidy. One would hope that the necessary political decisions, nevertheless, do not completely ignore economic laws and thus create unrealistic expectations. The resulting long-term consequences and distortions (as happened with natural gas regulation) might cause difficulties that compliance with the market might have avoided. 


\section{REFERENCES}

1. Daniel T. Spreng, "On Time, Information and Energy Conservation," ORAU/IEA-78-22(R), Institute for Energy Analysis, Oak Ridge Associated Universities, Oak Ridge, Tennessee, December 1978.

2. Willem van Gool, "Limits to Energy Conservation in Chemical Processes," ORAU/IEA-78-6(M), Institute for Energy Analysis, Oak Ridge Associated Universities, Oak Ridge, Tennessee, March 1978.

3. A. C. Meyers III and L. L. Vant-Hul1, "The Net Energy Analysis of the 100 MWe Commercial Solar Tower," Proceedings of the 1978 Annual Meeting of the American Section, International Solar Energy Society, Denver, Colorado, Volume 2.1, p. 786.

4. S. Baron, "Solar Energy: Will It Conserve Our Non-Renewable Resources?", Proceedings of the 1978 Annual Meeting of the American Section, International Solar Energy Society, Denver, Colorado, Volume 2.2, p. 617.

5. W. Devine, D. Boyd, W. Gilmer, "Economics and the Sun: Recognizing the Costs of Intermittency," unpublished report, Institute for Energy Analysis, Oak Ridge Associated Universities, Oak Ridge, Tennessee.

6. K. Cohen, "High Capital Cost: A Deterrent to Technological Change," presented at the International Scientific Forum for an Acceptable World Energy Future, Miami Beach, Florida, November 28, 1978.

7. V. Peterka, "Macrodynamics of Technological Change," RR-77-22, International Institute for Applied Systems Analysis, Laxenburg, Austria, November 1977.

8. R. H. Essenhigh, "Energy Use, Efficiency, and Conservation in Industry," Proceedings of the EPA/ERDA Symposium on Environment and Energy Conservation, Denver, Colorado, November 1975. EPA-600/2-76-212: ERDA-47, Washington, D. C., August 1976.

9. R. Winfrey, Economic Analysis of Highways; Inter. Textbook Co., Scranton, Pennsylvania, 1969.

10. A. Szalai, ed., The Use of Time, Mouton, The Hague, 1972.

11. Ontario Hydro, "Ontario Hydro Survey on Power System Reliability," Report No. PMA 76-5, Toronto, Canada, April 1977.

12. J. C. Fisher and R. H. Pry, "A Simple Substitution Model of Technological Change," Technical Information Series Report 70-C-215, General Electric Company, Research and Development Center, Schenectady, New York. 